\title{
Built Environment and Alzheimer. Quality Evaluation of Territorial Structures for Patients with Dementia
}

\author{
Andrea Brambilla ${ }^{1(\bowtie)}(\mathbb{D})$, Roberto Maino ${ }^{2}$, Silvia Mangili ${ }^{2}$, \\ and Stefano Capolongo ${ }^{1}$ (iD \\ ${ }^{1}$ Department ABC Architecture Built Environment Construction Engineering, \\ Cluster Design of Health Facilities, Design \& Health Lab, Politecnico di Milano, \\ via Ponzio 31, 20133 Milan, Italy \\ andreal.brambilla@polimi.it \\ 2 School of Architecture Urban Planning Construction Engineering, \\ Politecnico di Milano, Milan, Italy
}

\begin{abstract}
Sustainable, inclusive and resilient cities and urban settlements are fundamental in enabling people to live long and healthy lives. Elderly population is growing all over the world and in Italy is among the largest. Within this scenario, epidemiological data show that Alzheimer disease, a dementia which manifest with ageing, is also forecast to rapidly increase, up to 150 million cases in 2050. Within urban settlements, the health and socio-sanitary structures for elderly patients represent a fundamental social infrastructure that collects important investments but must be suitable to host people with dementia. The paper describes the methodology adopted for the definition of an assessment tool able to evaluate the indoor and outdoor qualities and characteristics of sociosanitary facilities for Alzheimer and elderly people. In the first phase the analysis of scientific literature, international case studies and sustainability assessment framework led to identification of 4 criteria, 19 indicators and 71 variables validated by experts in geriatry, psychiatry and architecture. In the second phase the tool has been operationalized and tested on a sample of three territorial structures in Lombardy Region, Italy. The outcomes of the evaluation can lead to the definition of sustainable project strategies.
\end{abstract}

Keywords: Ageing society $\cdot$ Dementia $\cdot$ Evaluation tool

\section{Introduction and Research Purpose}

Sustainable, inclusive and resilient cities and urban settlements are fundamental in enabling people to live longer and in a good state of health. Today, a significant share of the world's population is composed by elderly people. Therefore, fostering Sustainable Development Goals in terms of Sustainable Cities and Communities (SDGs No. 11) require specific actions toward ageing population needs [1]. Within this scenario, healthcare and socio-sanitary facilities represent a social infrastructure of great importance in a country like Italy in which the elderly population is among the largest in the world, with an increasing life expectancy, from 78.1 years old for men and 83.7 
for women in 2005 to the 80.8 years old for men and 85.2 for women of the 2018 [2]. Those facilities need to be sustainable and resilient to social, economic and technological changes such as the increasing prevalence of dementia diseases within contemporary ageing society. In particular Alzheimer is a disease which manifests itself with aging and affects $4-6 \%$ of over- 65 people [3, 4]. Epidemiological data highlight a continuous increase on a global scale and the trend does not show any drop with a forecast of 150 million cases in 2050 and an increase of 9,9 million every year [5, 6]. Alzheimer disease impacts on people memory, complex abilities and psychophysical abilities, therefore specific assistance need to be provided within specific healthcare infrastructures such as integrated domestic assistance, nursing homes, daily centres, villages or protected hospital wards which require high standard of quality and sustainability [7]. At the same time, healthcare is considered by developers and investors a valuable alternative asset class. Nursing homes and assisted homecare are indeed reported among the European and Italian top trends in real estate investments [8,9]. A high level of quality, social inclusion and environmental sustainability is therefore requested both by the market and by the people that are supposed to spend several years in there, often in fragile conditions. Built environment characteristics can indeed provide positive impacts on patients affected by dementia through green areas, environmental quality and wayfinding, as shown by Evidence Based Design (EBD) ${ }^{1}$ studies and the application of Gentlecare Method ${ }^{2}$. To the best of our knowledge, despite the growing importance of the topic, within the Italian regulatory system there are not reliable guidelines for what concerns the design, management and quality improvement of health facilities for the elderly. Therefore, the purpose of this research is to develop and validate an assessment tool for the quality evaluation of Italian socio-sanitary facilities and nursing homes for elderly patients affected by Alzheimer. The tool will be able to verify whether the existing territorial structures respond to the need of quality in terms of users wellbeing, sustainable management of spaces and activity provision. The tool will help stakeholders to understand where they should invest for improving quality and efficiency of their physical and organizational assets. This paper mainly explores the methodology adopted and briefly provide the preliminary results of the application.

\subsection{Methodology}

The methodological path has been developed in two subsequent phases. In the first phase an in-depth analysis has been conducted to understand the state of the art in terms of scientific production and physical realization.

\footnotetext{
${ }^{1}$ Evidence Based Design (EBD) can be defined as the process of explicitly use reliable evidence from research in making decisions about the design and management of built environment, together with an informed client. EBD related built environment qualities with medical or organizational outcomes $[10,11]$.

${ }^{2}$ The Gentlecare Method is prosthetic model of care and assistance that considers people, programs and physical space at the same time as resources for the assistance of dementia related diseases such as Alzheimer [12].
} 


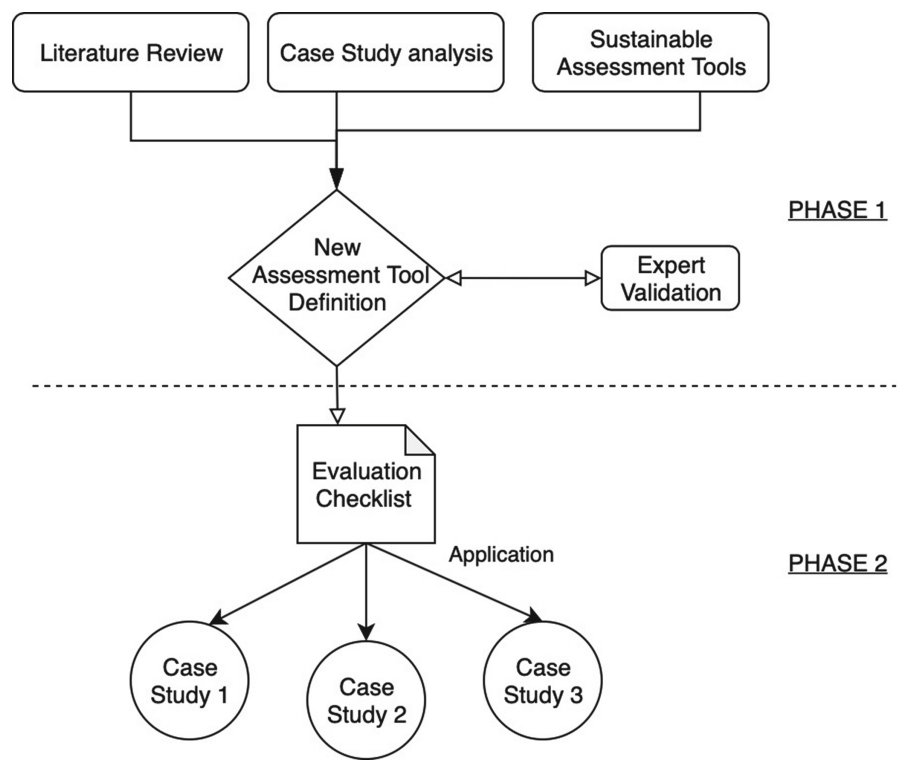

Fig. 1. Flow chart of the process followed in this study with the highlight of the two phases conducted

This phase includes the analysis of scientific literature, the evaluation and comparison of international case studies and the understanding of existing sustainability or quality assessment frameworks used in healthcare environments. From each of those analysis a series of criteria, indicators and variables have been collected to the definition of an assessment tool. The instrument has been reviewed and validated by relevant figures experienced on the topic. In the second phase an operative checklist for the assessment has been proposed and the tool has been tested on a sample of three territorial structures in Lombardy Region, Italy. A flow chart is hereafter provided to clarify the process followed (Fig. 1) and each phase is detailed described. As reported in empirical studies and literature reviews, there is strong evidence on the influence of specific physical features such as unit size, spatial layout, homelike character and domesticity on patients perception and wellbeing [13-17]. Other studies report that sensory stimulation, and environmental characteristics of social spaces also affect residents' behaviors [18-20]. Additionally, the importance of visual qualities improvement and noise and odour reduction is also highlighted in other studies [7, 19, 20]. People with dementia suffer disorientation and wandering therefore safety and orientation strategies are suggested by most of the papers collected, along with the provision of dedicated services and activities [21-24]. All the criteria that emerged from the literature have been collected and clustered in four macro-areas: Quality, Spaces, Activities and Wayfinding. 


\subsection{Case Study Analysis}

At the same time, the search of case studies, best practices and benchmark of excellence in the treatment of Alzheimer's patients has been conducted. An investigation on five case studies considered excellent in the European panorama for the care and support of Alzheimer's disease has been carried out. The analysis includes three Alzheimer Village (Hogway Dementia Village in The Netherlands, Landais Alzheimer Village, in France and Il Paese Ritrovato in Italy), a Day Care Centre (Day Care Centre in Spain) and an Alzheimer department in Nursery Home (Foyer La Grange in France). The best practice comparison confirms the four macro areas previously identified. Additionally, relevant design strategies applied in the five case studies have been considered as assessment criteria and led back to the four macro areas.

\subsection{Evaluation Tools Analysis}

Furthermore, existing evaluation tools have been analysed in order to understand how far the four macro-areas highlighted in the literature review and case study analysis are present in the available assessment methodologies. Originally grounded on sustainability assessment, those instruments are very important for the evaluation and improvement of the existing assets in terms of sustainability values, organization performances or healthrelated outcomes [25, 26]. Eight evaluation tools have been selected due to their relevance to the topic: BREEAM Building Research Establishment Environmental Assessment Method Healthcare version (UK, 2008); CHD-CHC Center for Health Design Community Health Center Evaluation tool (USA, 2017); DQI Design Quality Indicators for Healthcare (UK, 2012); EAT Environmental Audit Tool (Australia, 2003); LEED Leadership in Energy and Environmental Design Healthcare version (USA 2011); SustHealth Evaluation Tool (Italy, 2015); WELL International Building Standard (USA, 2011); TESS-NH Therapeutic Environment Screening Survey - Nursing Homes (USA, 1991). Only two of them specifically assess environments for patients suffering from dementia (EAT and TESS-NH). The analysis confirms the accuracy of the four macro areas identified with the addition of environmental sustainability topic. It also provides an insight of the evaluation method from both qualitative and quantitative approaches. Figure 2 offers a summary of the analysis conducted.

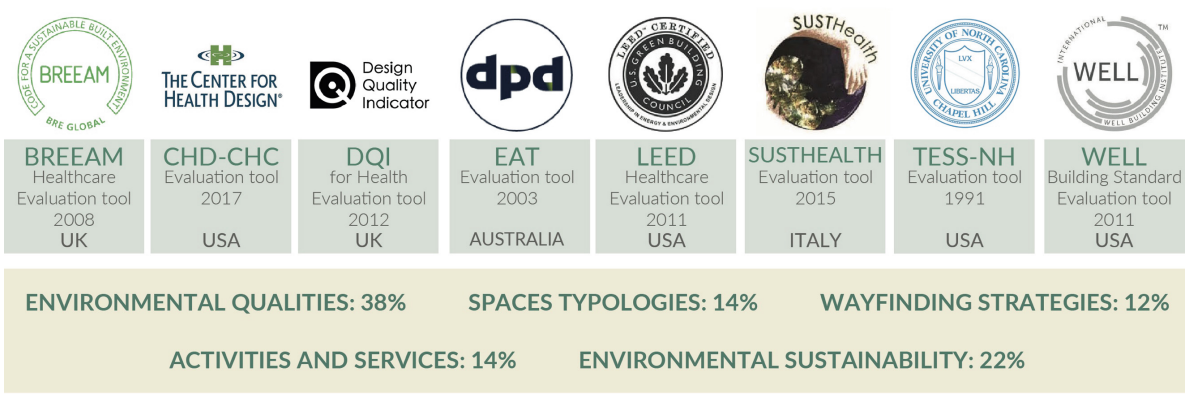

Fig. 2. Comparison of the international assessment tools selected. The percentage represent the number of indicators related to that specific topic retrospect to the total number of indicators. A fifth macro-area (environmental sustainability) emerges from this analysis. 


\section{The Assessment Tool}

\subsection{Tool Definition and Validation}

Starting from the analysis 4 macro areas (Quality, Space, Activities, Wayfinding), 19 criteria and 71 variables have been selected to compose the assessment tool. Sustainability aspects have been highlighted in the analysis but not included into the new tool since the topic is very well covered by existing assessment methodologies (i.e. LEED, BREEAM). The full list of criteria with the number of allocated variables is reported in Table 1 and an example of the evaluation variables.

Table 1. Assessment framework of macro areas and criteria with the number of evaluation variables allocated (in brackets)

\begin{tabular}{l|l|l|l}
\hline 1. Quality & 2. Space & 3. Activities & 4. Wayfinding \\
\hline 1.1 Views (5) & 2.1 Room (4) & 3.1 Garden (3) & 4.1 Control (4) \\
\hline 1.2 Noise (2) & 2.2 Garden (3) & 3.2 Relations (3) & 4.2 Paths (8) \\
\hline 1.3 Odour (1) & 2.3 Common areas (11) & 3.3 Physical activities (1) & 4.3 Signage (3) \\
\hline 1.4 Colours (3) & & 3.4 Food (3) & \\
\hline 1.5 Security (6) & & 3.5 Community (3) & \\
\hline 1.6 Domesticity (3) & & & \\
\hline 1.7 Scale (2) & & & \\
\hline 1.8 Perception (3) & & & \\
\hline
\end{tabular}

A first version of the instrument was inspected and validated by recognized experts from geriatric, psychology, healthcare architecture and management sectors.

\subsection{Application and Test on Italian Case Studies}

The second phase of the study concerned the application and test of the tool on a sample of case studies. Here, in order to operationalise the assessment, a checklist has been proposed. A numerical value between 0 and 4 is assigned to each criteria thanks to the fulfilment of one or more variables assessed either with a binary (i.e. presence or absence of therapeutic gardens) or with a ranking scale (i.e. percentage of single rooms). The final score, later expressed in percentage, is the sum of the scores obtained in each of the 71 variables. An example of scoring related to the variables previously mentioned in Table 2, is reported in Table 3. 
Table 2. Example of variables for the criterion 4.3 Signage in the macro area 4 Wayfinding

\begin{tabular}{l|l}
\hline $\begin{array}{l}\text { Macro } \\
\text { area }\end{array}$ & 4 Wayfinding \\
\hline Criterion & 4.3 Signage \\
\hline Variables & $\begin{array}{l}\text { 4.3.1 Are there signs and symbols that indicate univocally each indoor space (i.e. } \\
\text { toilet, rooms, common areas)? } \\
\text { 4.3.2 Signages are present also in outdoor areas? } \\
\end{array}$ \\
& $\begin{array}{l}\text { r.3.3 Private rooms are clearly identifiable by patients (i.e. names outside the } \\
\text { room, personal belongings hanged at the door, different colors)? }\end{array}$ \\
\hline
\end{tabular}

Table 3. Example of different scoring methodologies

\begin{tabular}{l|l|l|l|l|l|l}
\hline \multicolumn{2}{l|}{ Variables } & \multicolumn{2}{l|}{ Score } & \multicolumn{2}{l|}{} & $\begin{array}{l}\text { Total } \\
(\mathrm{max})\end{array}$ \\
\hline 4.3 .1 & $\begin{array}{l}\text { Are there signs and symbols that } \\
\text { indicate univocally each indoor } \\
\text { space? }\end{array}$ & No (0) & $\begin{array}{l}\text { Rooms } \\
(0.33)\end{array}$ & $\begin{array}{l}\text { Corridors } \\
(0,33)\end{array}$ & $\begin{array}{l}\text { Toilets } \\
(0.33)\end{array}$ & 1 point \\
\hline 4.3 .2 & $\begin{array}{l}\text { Signages are present also in } \\
\text { outdoor areas? }\end{array}$ & No (0) & Yes (1) & & 1 point \\
\hline 4.3 .3 & $\begin{array}{l}\text { Private rooms are clearly } \\
\text { identifiable by patients? }\end{array}$ & No (0) & $\begin{array}{l}\text { Cards } \\
(1)\end{array}$ & $\begin{array}{l}\text { Colors } \\
(1)\end{array}$ & $\begin{array}{l}\text { Hangers } \\
(1)\end{array}$ & 3 points \\
\hline
\end{tabular}

The checklist has been applied to three structures which are all accredited to the National Health System and located in Lombardy region. They have been selected because they differ in terms of period of construction and typology. Indeed, the Case Study 1 is a dedicated structure for patients with Alzheimer disease, opened about 10 years ago; the second (Case Study 2) is a 20 years old Alzheimer department; the third (Case Study 3) is an Alzheimer department in a 40 years old nursery home. The tool has been applied by the authors and the information have been collected thanks to the support of the staff and strategic direction including medical doctors, nurses and building managers. The results of this first application are briefly discussed below.

\subsection{Preliminary Results}

Overall, the most recent structure (Case Study 1) obtained $92 \%$ of acquittal while the other two have obtained respectively $65 \%$ for the independent nucleus (Case Study 2) while the Alzheimer nucleus realized by the reconversion of an existing department has obtained score equal to $75 \%$ (Case Study 3). Looking at the evaluation more in detail, considering the macro area Quality, the Case study 1 position itself as an excellent practice thanks to the domesticity provided by the materials and the wide use of natural light and the innovation given by the use of smart technologies both for facility management and for patient safety. Additionally, outdoor high-quality spaces, views and collateral activities are present and contribute to the achievement. On the contrary, in the less relevant cases several drawbacks have been highlighted such as the absence of single rooms or therapeutic gardens. It is also important to note that the structure that 
obtained a higher score is also the one that reported a high level of coordination during the project phase between architects, doctors and managers. This highlight the benefits of multidisciplinary in the design process of such settings. The comparison between the three settings is shown in Fig. 3.

\section{QUALITIES 2.SPACES 3.ACTIVITIES 4.WAYFINDING TOTAL SCORE}

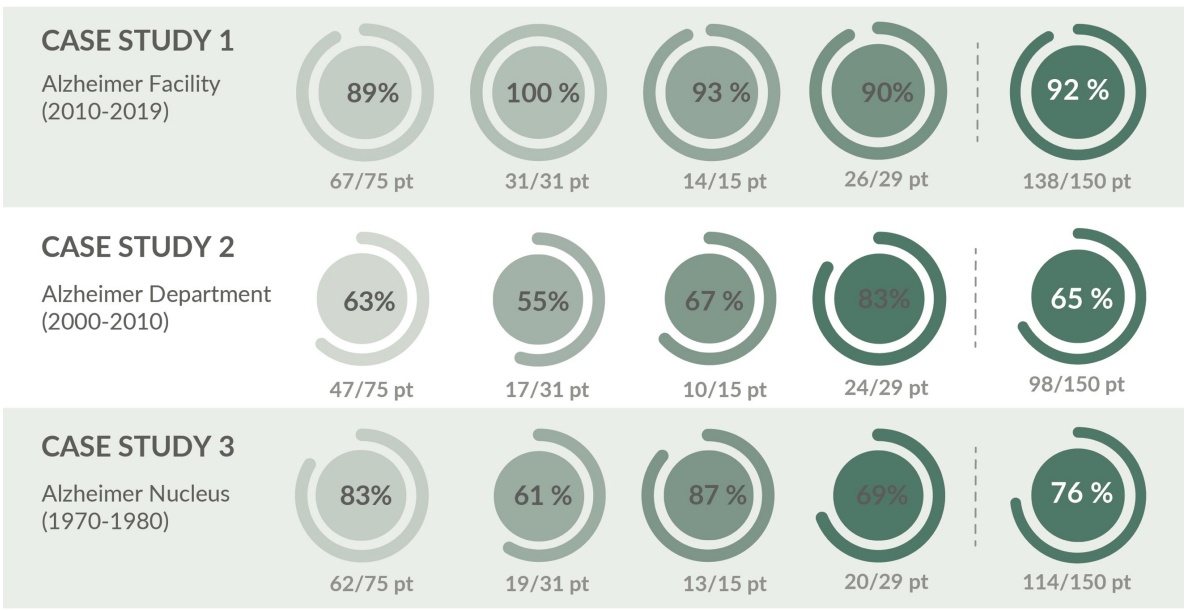

Fig. 3. Comparison of the assessment conducted on Case Study 1, 2 and 3

\section{Conclusions and Future Developments}

The preliminary results confirm and expand the knowledge in the field of healthcare architecture by defining a built environment quality assessment tool for evaluating territorial structures. This is the first study that use assessment methodologies for the quality evaluation of socio-sanitary facilities for Alzheimer in Italian context. The preliminary results on the three case studies can be further analysed in order to highlight the criticalities found and propose specific sustainable project strategies. In this way the tool can be very useful for supporting decision makers and facility managers in their strategic choices. Future tests on a wider sample are also encouraged.

Acknowledgements. The authors would like to acknowledge the following experts for the support granted during the tool definition: Prof. Dott. Marco Trabucchi (President Geriatric Research Group Brescia), Dott. Fascendini Sara (Medical Director Alzheimer excellence center Gazzaniga), Arch. Giovanni Ingrao (designer Alzheimer villages), Dott. Tiziana Mosso (Hospital Sanitary Manager, RSA Fondazione Honneger). 


\section{References}

1. World Health Organization: WHO Healthy Ageing and the Sustainable Development Goals. https://www.who.int/ageing/sdgs/en/. Accessed 28 Jan 2020

2. Quotidiano Sanità. Noi Italia 2019: Cresce speranza di vita per uomini e donne dove siamo al top in Ue, ultimi invece per fecondità. $\mathrm{Al} 12^{\circ}$ posto in Europa per la spesa sanitaria. Giù l'out of pocket. Istat. http://www.quotidianosanita.it/studi-e-analisi/articolo.php?articolo_id= 72993. Accessed 28 Jan 2020

3. Galluzzo, L., Gandin, C., Ghirini, S., Scafato, E.: Population ageing: opportunity or challenge? Centro Nazionale di Epidemiologia, Sorveglianza e Promozione della Salute, Istituto Superiore di Sanità, Roma Bollettino epidemiologico nazionale (2012). https://www. epicentro.iss.it/ben/2012/aprile/2. Accessed 28 Jan 2020

4. Izzicupo, F., Chattat, R., Gainotti, S., Carbone, G., Di Fiandra, T., Galeotti, F., MennitiIppolito, F., Raschetti, R., Vanacore, N.: Alzheimer: conoscere la malattia per saperla affrontare. Il Pensiero Scientifico Editore, Roma (2009)

5. Alzheimer's Disease International 2019. World Alzheimer Report 2019: Attitudes to dementia. Alzheimer's Disease International, London. https://www.alz.co.uk/research/ WorldAlzheimerReport2019.pdf. Accessed 28 Jan 2020

6. Falasca, C. (eds.): $2^{\circ}$ Rapporto sulle condizioni abitative degli anziani in Italia che vivono in case di proprietà - 2015. AUSER. http://www1.auser.it/wp-content/uploads/2015/11/ SECONDO\%20RAPPORTO\%20SULLE\%20CONDIZIONI\%20ABITATIVE\%20DEGLI \%20ANZIANI.pdf. Accessed 28 Jan 2020

7. Cannara, A., Brizioli, C., Brizioli, E.: Progettare l'ambiente per l'Alzheimer. Franco Angeli, Milano (2015)

8. Dezza, P.: Nelle residenze sanitarie il 5\% degli investimenti immobiliari. Il Sole 24 Ore. https://www.ilsole24ore.com. Accessed 28 Jan 2020

9. PwC and the Urban Land Institute. Emerging Trends in Real Estate ${ }^{\circledR}$ Europe 2019. PwC and the Urban Land Institute, London (2018). https://www.pwc.at/de/publikationen/branchenund-wirtschaftsstudien/pwc-emerging-trends-in-real-estate-europe-2019.pdf. Accessed 28 Jan 2020

10. Hamilton, D.K., Watkins, D.H.: Evidence-Based Design for Multiple Building Types. Wiley, Hoboken (2008)

11. Ulrich, R.S., Berry, L.L., Quan, X., Parish, J.T.: A Conceptual Framework for the Domain of Evidence-Based Design. HERD 4(1), 95-114 (2010)

12. Jones, M.: Il motodo Gentlecare. Carocci Faber, Roma (2008)

13. Chaudhury, H., Cooke, H.A., Cowie, H., Razaghi, L.: The Influence of the physical envirnment on residents with dementia in long-term care settings: a review of the empirical literature. Gerontologist 58(5), e325-e337 (2017). https://doi.org/10.1093/geront/gnw259

14. Chrysikou, E.: From Normalisation theory to a "fit for purpose" architecture for mental ill. World Health Des. 5(3), 72-80 (2012)

15. Davis, S., Byers, S., Nay, R., Koch, S.: Guiding design of dementia friendly environments in residential care settings. Dementia 8(2), 185-203 (2009)

16. Milte, R., Shulver, W., Killington, M., Bradleya, C., Ratcliffe, J., Crottyab, M.: Quality in residential care from the perspective of people living with dementia: the importance of personhood. Arch. Gerontol. Geriatr. 63, 9-17 (2016)

17. Orfield, S.J.: Dementia environment design in seniors housing: optimizing resident perception and cognition. Seniors Hous. Care J. 23(1), 58-69 (2015)

18. Marquardt, G., Bueter, K., Motzek, T.: Impact of the design of the built environment on people with dementia: an evidence-based review. HERD 8(1), 127-157 (2014) 
19. Marquardt, G., Schmieg, P.: Dementia-friendly architecture: environments that facilitate wayfinding in nursing homes. Am. J. Alz. Dis. Other Dementias 24(4), 333-340 (2009)

20. Leung, M., Wang, C., Chan, I.Y.S.: A qualitative and quantitative investigation of effects of indoor built environment for people with dementia in care and attention homes. Build. Environ. 157, 89-100 (2019)

21. Anderiesen, H., Scherder, E.J.A., Goossens, R.H.M., Sonnoveld, M.H.: A systematic review - physical activity in dementia: the influence of the nursing home environment. Appl. Ergonomics 45, 1678-1686 (2014)

22. Van Hoof, J., Helianthe, S.M.K., Duijnstee, M.S.H., et al.: The indoor environment and the integrated design of homes for older people with dementia. Build. Environ. 45(5), 1244 1261 (2010)

23. de Boer, B., Hamers, J.P.H., Zwakhalen, S.M.G., Tan, F.E.S., Verbeek, H.: Quality of care and quality of life of people with dementia living at green care farms: a cross-sectional study. BMC Geriatr. 17, 155 (2017)

24. Jarrott, S., Gigliotti, C.M.: Comparing responses to horticultural-based and traditional activities in dementia care programs. Am. J. Alz. Dis. Other Dementias 25(8), 657-665 (2010)

25. Brambilla, A., Buffoli, M., Capolongo, S.: Measuring hospital qualities. Acta bio-medica 90(9S), 54-63 (2019)

26. Brambilla, A., Capolongo, S.: Healthy and sustainable hospital evaluation - a review of POE tools for hospital assessment in an evidence-based design framework. Buildings 9(4), 76 (2019)

Open Access This chapter is licensed under the terms of the Creative Commons Attribution 4.0 International License (http://creativecommons.org/licenses/by/4.0/), which permits use, sharing, adaptation, distribution and reproduction in any medium or format, as long as you give appropriate credit to the original author(s) and the source, provide a link to the Creative Commons license and indicate if changes were made.

The images or other third party material in this chapter are included in the chapter's Creative Commons license, unless indicated otherwise in a credit line to the material. If material is not included in the chapter's Creative Commons license and your intended use is not permitted by statutory regulation or exceeds the permitted use, you will need to obtain permission directly from the copyright holder.

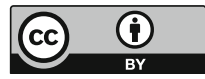

